\title{
Reduction of intra-hospital transport time using the easy tube arrange device
}

\author{
Ki Hyuk Joo, In Sool Yoo, Jinwoong Lee, Seung Whan Kim, Seung Ryu, \\ Yeon Ho You, Yong Chul Cho, Woon Jun Jeong, Byung Jun Ahn, \\ Sung Uk Cho
}

Department of Emergency Medicine, Chungnam National University School of Medicine, Daejeon, Korea

Objective Critically ill patients sometimes require transport to another location. Longer intrahospital transport time increases the risk of hemodynamic instability and associated complications. Therefore, reducing intra-hospital transport time is critical. Our objective was to evaluate whether or not a new device the easy tube arrange device (ETAD) has the potential to reduce intra-hospital transport time of critically ill patients.

Methods We enrolled volunteers for this prospective randomized controlled study. Each participant arranged four, five, and six fluid tubings, monitoring lines, and therapeutic equipment on a cardiopulmonary resuscitation training mannequin (Resusci Anne). The time required to arrange the fluid tubings for intra-hospital transport using two different methods was evaluated.

Results The median time to arrange four, five, and six fluid tubings was 86.00 (76.50 to 98.50), 96.00 (86.00 to 113.00), and 115.50 (93.00 to 130.75) seconds, respectively, using the conventional method and 60.50 (52.50 to 72.75), 69.00 (57.75 to 80.80), and 72.50 (64.75 to 90.50) seconds using the ETAD (all $\mathrm{P}<0.001$ ). The total duration (for preparing the basic setting and organizing before and after the transport) was 280.00 (268.75 to 293.00), 315.50 (304.75 to 330.75), and 338.00 (319.50 to 360.25 ) seconds for four, five, and six fluid tubings, respectively, using the conventional method and 274.50 (261.75 to 289.25), 288.00 (271.75 to 298.25), and 301.00 (284.50 to 310.75) seconds, respectively, using the new method $(P=0.024, P<0.001$, and $P<0.001$, respectively).

Conclusion The ETAD was convenient to use, reduced the time to arrange medical tubings, and is expected to assist medical staff during intra-hospital transport.

Keywords Critical illness; Equipment and supplies; Transportation of patients

Capsule
Wummary is already known
$\begin{aligned} & \text { Longer intra-hospital transport time increases the risk of hemodynamic insta- } \\ & \text { bility and impending complications. Therefore, reducing intra-hospital trans- } \\ & \text { port time is an important issue in patient transport. }\end{aligned}$
$\begin{aligned} & \text { What is new in the current study } \\ & \text { The newly invented easy tube arrange device reduces the time to organize be- } \\ & \text { fore and after the intra-hospital transport compared to the conventional meth- } \\ & \text { od. Also, using the easy tube arrange device assists medical staff during the in- } \\ & \text { tra-hospital transports and is convenient. }\end{aligned}$

Received: 13 December 2015 Revised: 6 February 2016

Accepted: 7 February 2016

Correspondence to: Sung Uk Cho Department of Emergency Medicine, Chungnam National University Hospital, 282 Munhwa-ro, Jung-gu, Daejeon 35015, Korea

E-mail:mp5medical@naver.com

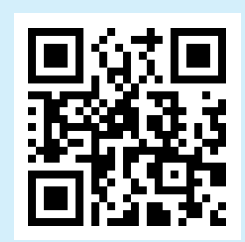

How to cite this article:

Joo KH, Yoo IS, Lee J, Kim SW, Ryu S, You YH, Cho YC, Jeong WJ, Ahn BJ, Cho SU. Reduction of intra-hospital transport time using the easy tube arrange device. Clin Exp Emerg Med 2016;3(2):81-87.

This is an Open Access article distributed under the terms of the Creative Commons Attribution Non-Commercial License (http:// creativecommons.org/licenses/by-nc/4.0/). 


\section{INTRODUCTION}

Approximately $80 \%$ of the patients admitted to the hospital receive intravenous injections for various reasons including hydration, electrolytes, medication, transfusion, and nutrition. ${ }^{1,2} \mathrm{~Pa}-$ tients under intensive care not only receive more injections but also often have more equipment attached to them, including electrocardiography, oxygen saturation, noninvasive blood pressure, central venous pressure (CVP), and intra-arterial blood pressure monitoring devices. Critically ill patients are often transported to alternate locations within the hospital for additional examinations or operations, which induces a higher risk of hemodynamic instability and side effects. ${ }^{3-10}$ Doring et al. ${ }^{11}$ have reported that the increase in transportation time and the number of fluids and tubes lead to an increase in side effects.

$\mathrm{Kim}^{12}$ analyzed the daily tasks of nurses and reported that the largest proportion (29.93\%) consists of taking vital signs (on average 9.84 times a day) followed by transporting patients (on average 4.16 times a day). Evidently, transport of the patients for examinations, operations, and admission take up a majority of the nurses' daily tasks, considering the difficulties and inconvenience in organizing fluids in addition to vital sign monitoring and managing therapeutic equipment lines.

A new device, the easy tube arrange device (ETAD), was developed to ease the organization and transportation of fluids tubes, and the objective of this study was to evaluate its effectiveness in reducing intra-hospital transport time and assisting nurses in job performance.

\section{METHODS}

\section{Study subjects}

For this study, nurses and emergency medical technicians (EMTs) responsible for transporting patients were contacted via email, and 46 who responded voluntarily participated. This study was a
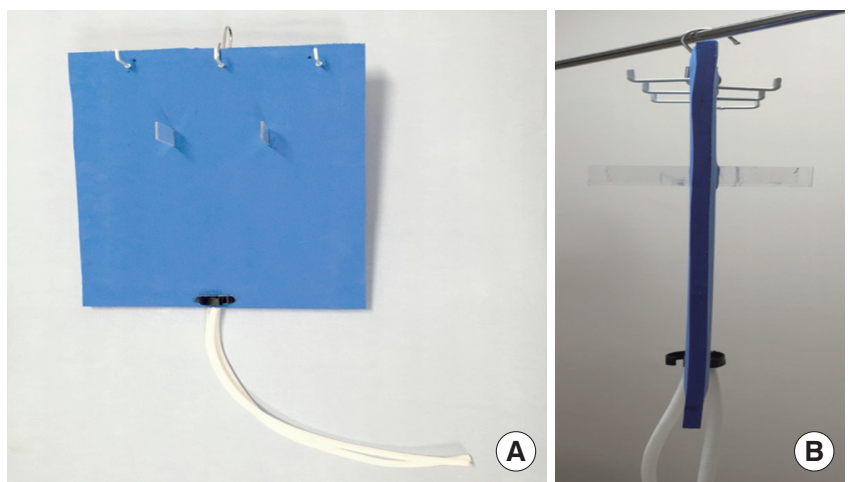

Fig. 1. Easy tube arrange device: (A) front view and (B) side view. simulation that did not require the participants' personal information or affect their health. Therefore, approval procedures were omitted by the ethics committee of the institutional review board.

\section{The newly invented ETAD}

To support the weight of the fluids, the ETAD is made of a $400 x$ $400 \times 5 \mathrm{~mm}$ acrylic board with $500 \times 500 \times 3 \mathrm{~mm}$ ethylene vinyl acetate foam attached on both sides to prevent injuries in case it falls on a patient. Each side of the board can hold up to three fluids. A clip is attached at the bottom to gather the fluid lines, and corrugated tubing is installed below to insert and organize the fluids tubes (Figs. 1, 2).

\section{Basic setting}

As the basic setting, each volunteer was assigned to prepare the cardiopulmonary resuscitation training mannequin (Resusci Anne; Laerdal Medical, Wappingers Falls, NY, USA) for transport with equipment for electrocardiography, oxygen saturation, automated blood pressure, CVP, and continuous arterial pressure monitoring as well as an oxygen supplier and syringe pump. The conventional and the new method using ETAD were assigned. Each method consisted of four, five, or six fluids, resulting in a total of six basic conditions (one fluid for CVP, one fluid for maintaining an arterial catheter, and one fluid for peripheral veins were included in each condition). The mannequin's artificial skin was pierced to insert the CVP and arterial pressure catheters (Fig. 3).

\section{Methods and measurements}

From this basic setting, injection pumps and fluids needed for monitoring CVP and continuous arterial pressure were moved to
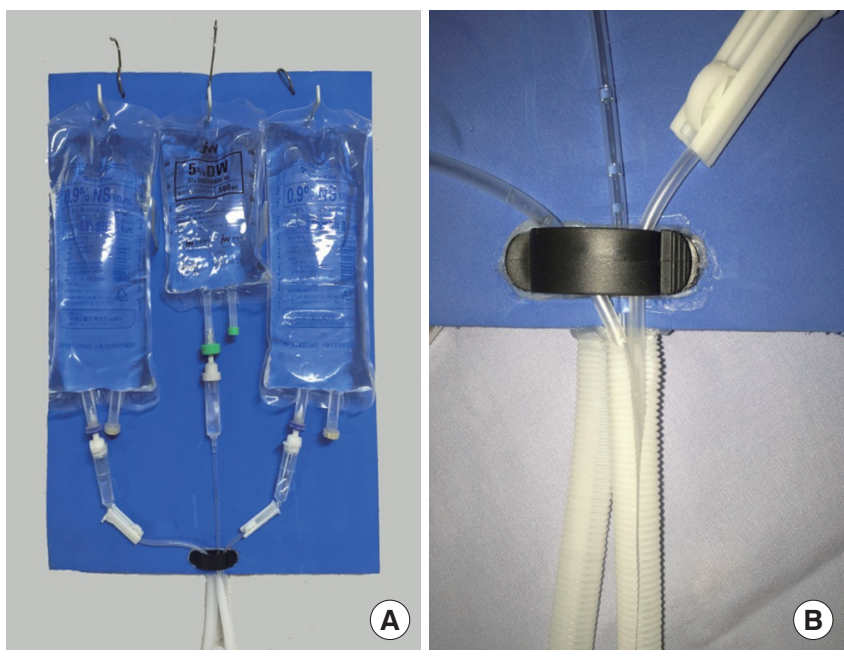

Fig. 2. Set-up of fluids and tubings on the easy tube arrange device: (A) overview showing three fluid bags hanging on the easy tube arrange device and (B) multiple tubings in corrugated tubing. 


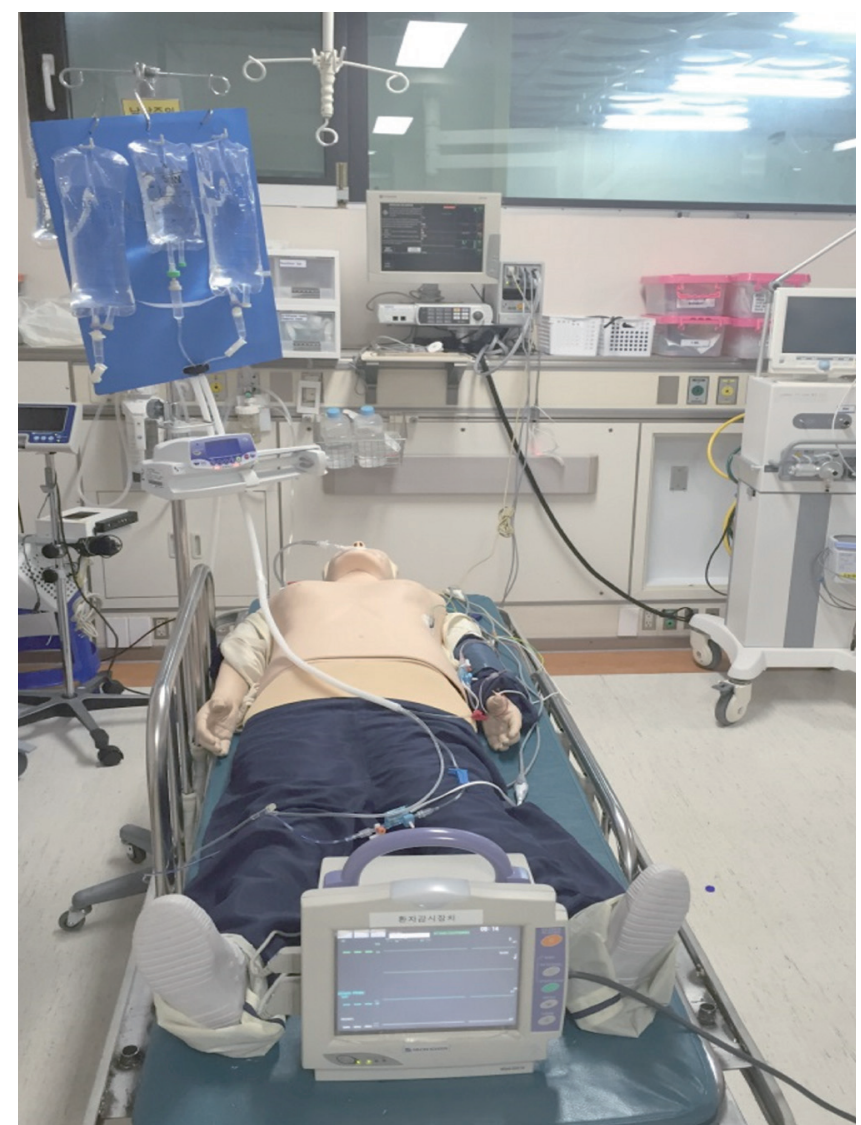

Fig. 3. Resusci Anne with medical fluids and monitoring systems.

the portable stand, and the monitoring equipment from the central monitor was moved to the portable monitor. The study subjects randomly selected the recording sheets with the order of the method and the number of fluids.

We measured transport time divided into three steps: (1) preparation of the basic setting (as defined above in Basic setting), (2) preparation for transport, and (3) return to the basic setting. Total transport duration was calculated as the sum of the times for the three steps (Fig. 4).

The time for preparation for transport was measured from the initial point of contact of the fluids or vital sign monitoring and therapeutic equipment to the point when the transport was completed and the hands were off of the fluids and vital sign monitoring and therapeutic equipment. The time for return (restoration back to the basic setting after the transport) was measured from the initial point of contact of the fluids and vital sign monitoring and therapeutic equipment to the completion, when the hands were off of the fluids and vital sign monitoring and treatment devices.

The time it takes to transport by the conventional method was measured three times for each method and for each count of flu-

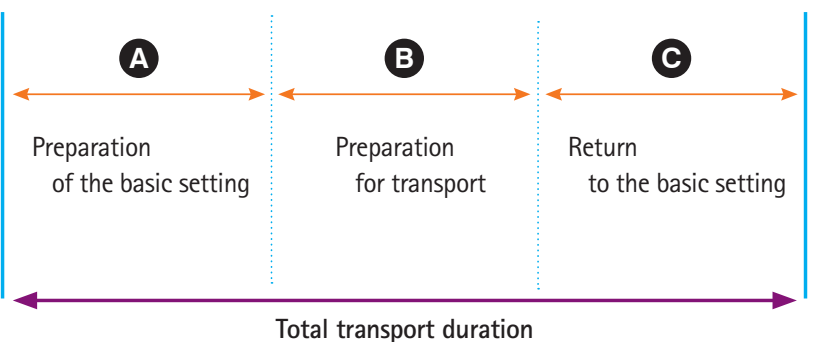

Fig. 4. Time measurement of three steps: (A) preparation of the basic setting, (B) preparation for transport, and (C) return to the basic setting.

Table 1. General characteristics of the volunteers

\begin{tabular}{lc}
\hline Characteristics & Value \\
\hline Sex & \\
Male & $18(39.1)$ \\
Female & $28(60.9)$ \\
Type of occupation & \\
$\quad$ Nurse & $36(78.3)$ \\
Emergency medical technician & $10(21.7)$ \\
Work duration (mo) & $21.50 \pm 14.64$ \\
\hline
\end{tabular}

Values are presented as number (\%) or mean \pm standard deviation.

ids. Time was measured in seconds, rounded to two decimal places. The convenience of each method was evaluated using a verbal numeric scale from 0 to 10 (worst to best).

\section{Statistical analysis}

For the statistical analysis, IBM SPSS Statistics ver. 19.0 (IBM Corp., Armonk, NY, USA) was used. To analyze the normally distributed variables for each group's duration, a paired t-test was applied, and the Wilcoxon signed ranks test was used to analyze the variables that were not normally distributed. In analyzing the characteristics of the volunteers and the duration of two methods, the Mann-Whitney U-test was used for sex and occupation, whereas Spearman's correlation coefficient was used to compare the participants' experience. The Shapiro-Wilk test was applied to test normality. For each analysis, the result was considered statistically significant when the P-value was $<0.05$.

\section{RESULTS}

\section{General characteristics of the study participants}

This study was conducted from May 4 through May 29, 2015, with 46 emergency room nurses and EMTs: 18 (39.1\%) men and 28 (60.9\%) women and 36 (78.3\%) nurses and 10 (21.7\%) EMTs. The average work experience was $21.50 \pm 14.64$ months (Table 1). 
Comparison of times to prepare the basic setting using the conventional method and the new method using ETAD

Using the conventional method, the median and interquartile range for the time to preparation of the basic setting was 192.00 (187.75 to 201.50) seconds for four fluids, 218.00 (205.00 to 230.00) seconds for five fluids, and 220.00 (210.75 to 225.25 ) seconds for six fluids, whereas the new method using ETAD took 210.00 (200.00 to 225.25 ), 215.00 (205.00 to 226.00), and 219.50 (209.75 to 233.50) seconds, respectively. A statistically significant difference was observed for four fluids $(P<0.001)$, but no significant difference was identified for five and six fluids $(P=0.942$ and 0.795 , respectively) (Table 2).

\section{Comparison of transport preparation and return times using the conventional method and the new method using ETAD}

Using the conventional method, the median and interquartile range for the preparation time was 38.00 (34.75 to 47.00 ) seconds for four fluids, 46.00 (41.00 to 52.00) seconds for five fluids, and 55.00 (44.00 to 65.00 ) seconds for six fluids, whereas the new method using ETAD took 28.50 (25.00 to 32.75 ), 32.50 (27.00 to 37.50 ), and 35.00 ( 30.75 to 42.00 ) seconds, respectively, all showing statistically significant differences (all $\mathrm{P}<0.001$ ).

Using the conventional method, the return times were 46.50 (41.00 to 52.00), 50.00 (44.50 to 58.75), and 59.50 (49.00 to 64.75) seconds, respectively, for four, five, and six fluids, whereas using the new method using ETAD, the return times were 33.00 (37.75 to 39.00 ), 35.50 (30.75 to 42.00 ), and 39.00 (34.00 to 48.00 ) seconds, respectively, all showing statistically significant differences (all $\mathrm{P}<0.001$ ) (Table 2).

\section{Comparison of the total transport duration using the conventional method and the new method using ETAD} For the conventional method, the total duration was 280.00 (268.75 to 293.00), 315.50 (304.75 to 330.75), and 338.00 (319.50 to 360.25) seconds, respectively, for four, five, and six fluids, whereas the new method took 274.50 (261.75 to 289.25), 288.00 (271.75 to 298.25), and 301.00 (284.50 to 310.75$)$ seconds, respectively, all showing statistically significant differences $(P=0.024, P<0.001$, and $\mathrm{P}<0.001$, respectively) (Table 2 ).

Table 2. Comparison of transport times using conventional method and the new method with the ETAD

\begin{tabular}{|c|c|c|c|c|}
\hline & \multirow{2}{*}{ No. of fluids } & \multicolumn{2}{|c|}{ Time (sec) } & \multirow{2}{*}{ P-value } \\
\hline & & Conventional method & ETAD & \\
\hline \multirow[t]{2}{*}{ Preparation of basic setting } & 4 & 192.00 (187.75-201.50) & $210.00(200.00-225.25)$ & $<0.001$ \\
\hline & 6 & $220.00(210.75-225.25)$ & $219.50(209.75-233.50)$ & 0.795 \\
\hline \multirow[t]{2}{*}{ Preparation for transport } & 4 & $38.00(34.75-47.00)$ & $28.50(25.00-32.75)$ & $<0.001$ \\
\hline & 5 & $46.00(41.00-52.00)$ & $32.50(27.00-37.50)$ & $<0.001$ \\
\hline \multirow{2}{*}{ Return to basic setting } & 5 & $50.00(44.50-58.75)$ & $35.50(30.75-42.00)$ & $<0.001$ \\
\hline & 6 & $59.50(49.00-64.75)$ & $39.00(34.00-48.00)$ & $<0.001$ \\
\hline \multirow[t]{3}{*}{ Total transport duration } & 4 & $280.00(268.75-293.00)$ & $274.50(261.75-289.25)$ & 0.024 \\
\hline & 5 & $315.50(304.75-330.75)$ & $288.00(271.75-298.25)$ & $<0.001$ \\
\hline & 6 & $338.00(319.50-360.25)$ & $301.00(284.50-310.75)$ & $<0.001$ \\
\hline
\end{tabular}

Values are presented as median (interquartile range).

ETAD, easy tube arrange device.

Table 3. Comparisons of transport times using the conventional method and the new method using ETAD according to participant characteristics

\begin{tabular}{|c|c|c|c|c|c|c|c|}
\hline \multirow{2}{*}{ Method } & \multirow{2}{*}{$\begin{array}{l}\text { No. of } \\
\text { fluids }\end{array}$} & \multicolumn{2}{|c|}{ Time (sec) } & \multirow{2}{*}{ P-value } & \multicolumn{2}{|c|}{ Time (sec) } & \multirow{2}{*}{ P-value } \\
\hline & & Male & Female & & Nurse & EMT & \\
\hline \multirow[t]{3}{*}{ Conventional } & 4 & 85.50 (78.75-108.25) & $86.50(72.75-97.50)$ & 0.069 & 85.50 (77.25-97.75) & $90.00(57.75-110.75)$ & 0.865 \\
\hline & 5 & $96.50(85.25-114.75)$ & $95.50(86.50-111.25)$ & 0.710 & 94.50 (85.25-105.75) & $111.00(90.25-122.25)$ & 0.091 \\
\hline & 6 & $123.50(97.50-140.75)$ & $112.50(93.00-126.25)$ & 0.251 & $112.00(92.25-125.75)$ & 136.00 (108.00-164.50) & 0.156 \\
\hline \multirow[t]{3}{*}{ ETAD } & 4 & $59.00(50.75-73.25)$ & $60.50(55.25-74.00)$ & 0.677 & $61.00(53.50-71.75)$ & $60.00(48.00-77.25)$ & 0.665 \\
\hline & 5 & $64.50(57.75-75.50)$ & $69.50(57.75-83.25)$ & 0.424 & $69.00(58.50-79.50)$ & $67.00(53.25-98.75)$ & 0.894 \\
\hline & 6 & 71.00 (64.75-85.50) & 77.00 (63.50-94.25) & 0.628 & 71.00 (63.00-87.75) & $83.00(67.50-110.25)$ & 0.156 \\
\hline
\end{tabular}

Values are presented as median (interquartile range).

ETAD, easy tube arrange device; EMT, emergency medical technician. 
Comparison of the total transport duration using the conventional method and the new method using ETAD according to the characteristics of the participants

Regarding the time it took to restore the basic setting before and after the transport, there were no statistically significant differences between men and women or between nurses and EMTs using either method (Table 3).

In the correlation analysis based on participant experience, the correlation coefficients for the time it took to restore the basic setting before and after the transport using the conventional method were $-0.130,0.810$, and $-0.820(P=0.391,0.593$, and $0.589)$ for four, five, and six fluids, respectively, and for the new method using ETAD were $-0.038,0.069$, and $0.137(P=0.803$, 0.648 , and 0.366 ), respectively, showing no statistically significant correlation between experience and duration.

\section{User evaluation comparison of the conventional method and new method using ETAD}

The new method using ETAD was evaluated to be more convenient as the conventional method received a score of 3.0 (2.0 to 4.0) for convenience, whereas the new method scored 8.0 (6.0 to 8.0), showing a statistically significant difference $(P<0.001)$.

\section{DISCUSSION}

The intra-hospital transport of critically ill patients occurs frequently for examinations and therapeutic operations. Side effects such as decreased oxygen saturation, low blood pressure, arrhythmia, myocardial infarction, and detachment of the therapeutic equipment occur during intra-hospital transport. According to Parmentier-Decrucq et al.., ${ }^{13} 232$ of 262 intensive care unit patients were transported for a computed tomography scan; 128 patients were transported once, whereas the remaining patients experienced two or more intra-hospital transports, and $45.8 \%$ of them reported one or more adverse events. Other studies have reported that adverse events occur in 6\% to $71.1 \%$ of the transports. ${ }^{5-8,14-20}$ According to a recently published multi-organization cohort study, 1,782 of 6,242 intensive care unit patients (28.5\%) experienced intra-hospital transport. The frequency of transport was 3,687 times, indicating $1.7 \pm 1.3$ transports per patient. Also, the transported patients had a higher chance of experiencing adverse events (odds ratio, 1.9; 95\% confidence interval, 1.7 to 2.2; $\mathrm{P}<0.001$ ). A computed tomography scan was the most frequent reason for intra-hospital transport, accounting for 2,870 transports (93.6\%), followed by 161 transports for magnetic resonance imaging, 11 for angiography, four for nuclear medicine examination, and 20 for various other reasons. ${ }^{21}$ Therefore, the risk of ad- verse events that can occur during the intra-hospital transport and the benefit of diagnosis or therapeutic treatment must be well evaluated in advance. ${ }^{22}$

Many studies have been conducted to develop an effective method to reduce the risk of adverse events caused by intra-hospital transport. These studies include stabilizing a patient's condition before transport, ${ }^{21-24}$ checking equipment before transport, ${ }_{1}^{20,25}$ maintaining appropriate patient condition during transport, ${ }_{1}^{25}$ being accompanied by an expert practitioner with experience, ${ }_{1}^{20,25}$ utilizing a transport protocol, ${ }_{1}^{26}$ and placing the examination and treatment rooms in the vicinity of the emergency room or intensive care unit. ${ }^{20,25}$ Based on these studies, a device to reduce the transport time and the workload of the nurses was designed to conduct this study.

We found that the time it takes to organize the fluids and tubings and vital sign monitoring and therapeutic equipment before and after the intra-hospital transport was reduced using the newly invented ETAD method over the conventional method. The time it takes to prepare at the beginning was shorter using the conventional method with four fluids, although there was no statistically significant difference for five or six fluids. When not many fluids and tubings are involved, the new method using ETAD takes more time because the tubings must be inserted into the corrugated tubing. However, as the number of fluids increase, the conventional method consumes more time because the tubes get entangled. According to a previous study, hemodynamic instability increases with longer transport time. ${ }^{11}$ The newly invented ETAD can be used to reduce intra-hospital transport time, further reducing the frequency of adverse events resulting from the transportation. The reduced time by using ETAD is small in proportion to the total transport duration, but considering the transport distance within the emergency department is relatively short, tens of seconds can be important. Although there were several previous studies on reducing complications during transport, this study is the first to evaluate a device aimed at reducing transport time. Consequently, this study may be much more relevant to patient transport.

Lastly, according to the participant's survey, the newly invented ETAD is more convenient to use compared with the conventional method and therefore can assist the medical staff conducting the intra-hospital transports.

This study has some limitations. First, although the number of monitoring or therapeutic devices varies depending on the condition of the patient, we used the same number throughout our study. Second, unintentional detachment of the fluid tubing, vital sign monitoring devices, or therapeutic equipment; malfunctioning of the syringe pump, and technical errors were not consid- 
ered. This should be evaluated through further study. Third, after transporting to the alternate location for an examination or therapeutic operation, the process of moving the patients to the examination/therapeutic bed and back to the wheeled stretcher was not included. Technical errors, as well as severe entangling of the fluid tubing, vital sign monitoring devices, and therapeutic equipment, often occur while the patients are moved from the wheeled bed to another station. If these processes were included, the newly invented ETAD may have shown a greater reduction in time and decreased the technical errors compared with the conventional method. Further studies including these processes are needed. Lastly, opaque corrugated tubing was used for organizing the tubes. Because the fluid tubes were not visible, issues such as formation of air bubbles were not detected. However, this issue can be resolved by replacing with transparent corrugated tubing.

The newly invented ETAD reduces the time to organize fluids and their tubing before and after the intra-hospital transport compared with the conventional method. Also, the ETAD is convenient to use and assists medical staff during the intra-hospital transport. Further studies on its effectiveness in inter-hospital transport and in actual patients are needed.

\section{CONFLICT OF INTEREST}

No potential conflict of interest relevant to this article was reported.

\section{REFERENCES}

1. Kim H, Chaung SK, Kim K, Kang K. The relationship of pain, depression and anxiety which patients recognize on intravenous injection: focus on pain relating factors. J Korean Acad Fundam Nurs 2007;14:306-14.

2. Younger G, Khan M. Setting up and priming an intravenous infusion. Nurs Stand 2008;22:40-4.

3. Waydhas C. Intrahospital transport of critically ill patients. Crit Care 1999;3:R83-9.

4. Olson CM, Jastremski MS, Vilogi JP, Madden CM, Beney KM. Stabilization of patients prior to interhospital transfer. Am J Emerg Med 1987;5:33-9.

5. Braman SS, Dunn SM, Amico CA, Millman RP. Complications of intrahospital transport in critically ill patients. Ann Intern Med 1987;107:469-73.

6. Smith I, Fleming S, Cernaianu A. Mishaps during transport from the intensive care unit. Crit Care Med 1990;18:278-81.

7. Insel J, Weissman C, Kemper M, Askanazi J, Hyman Al. Cardiovascular changes during transport of critically ill and postop- erative patients. Crit Care Med 1986;14:539-42.

8. Andrews PJ, Piper IR, Dearden NM, Miller JD. Secondary insults during intrahospital transport of head-injured patients. Lancet 1990;335:327-30.

9. Harrahill M, Bartkus E. Preparing the trauma patient for transfer. J Emerg Nurs 1990;16:25-8.

10. Hurst JM, Davis K Jr, Johnson DJ, Branson RD, Campbell RS Branson PS. Cost and complications during in-hospital transport of critically ill patients: a prospective cohort study. J Trauma 1992;33:582-5.

11. Doring BL, Kerr ME, Lovasik DA, Thayer T. Factors that contribute to complications during intrahospital transport of the critically ill. J Neurosci Nurs 1999;31:80-6.

12. Kim EJ. Work analysis for the role of the emergency department nurses. J Korean Acad Nurs 1998;28:93-103.

13. Parmentier-Decrucq E, Poissy J, Favory R, et al. Adverse events during intrahospital transport of critically ill patients: incidence and risk factors. Ann Intensive Care 2013;3:10.

14. Wallen E, Venkataraman ST, Grosso MJ, Kiene K, Orr RA. Intrahospital transport of critically ill pediatric patients. Crit Care Med 1995;23:1588-95.

15. Indeck M, Peterson S, Smith J, Brotman S. Risk, cost, and benefit of transporting ICU patients for special studies. J Trauma 1988;28:1020-5.

16. Szem JW, Hydo $\amalg$, Fischer E, Kapur S, Klemperer J, Barie PS. High-risk intrahospital transport of critically ill patients: safety and outcome of the necessary "road trip". Crit Care Med 1995;23:1660-6.

17. Stearley HE. Patients' outcomes: intrahospital transportation and monitoring of critically ill patients by a specially trained ICU nursing staff. Am J Crit Care 1998;7:282-7.

18. Evans $A$, Winslow EH. Oxygen saturation and hemodynamic response in critically ill, mechanically ventilated adults during intrahospital transport. Am J Crit Care 1995;4:106-11.

19. Weg JG, Haas CF. Safe intrahospital transport of critically ill ventilator-dependent patients. Chest 1989;96:631-5.

20. Lahner D, Nikolic A, Marhofer $P$, et al. Incidence of complications in intrahospital transport of critically ill patients: experience in an Austrian university hospital. Wien Klin Wochenschr 2007;119:412-6.

21. Schwebel C, Clec'h C, Magne S, et al. Safety of intrahospital transport in ventilated critically ill patients: a multicenter cohort study. Crit Care Med 2013;41:1919-28.

22. Marques A. Avoiding harm during intra- and inter-hospital transport. In: Chiche JD, Moreno R, Putensen C, et al. editors. Patient safety and quality of care in intensive care medicine. Berlin: Medizinisch Wissenschaftliche Verlagsgesellschaft; 
2009. p.405-18.

23. Lovell MA, Mudaliar MY, Klineberg PL. Intrahospital transport of critically ill patients: complications and difficulties. Anaesth Intensive Care 2001;29:400-5.

24. Papson JP, Russell KL, Taylor DM. Unexpected events during the intrahospital transport of critically ill patients. Acad Emerg Med 2007;14:574-7.
25. Warren J, Fromm RE Jr, Orr RA, Rotello LC, Horst HM; American College of Critical Care Medicine. Guidelines for the inter- and intrahospital transport of critically ill patients. Crit Care Med 2004;32:256-62.

26. Fanara B, Manzon C, Barbot O, Desmettre T, Capellier G. Recommendations for the intra-hospital transport of critically ill patients. Crit Care 2010;14:R87. 